\title{
UM OLHAR SOBRE A FAMÍLIA NA PERSPETIVA SISTÉMICA O PROCESSO DE COMUNICAÇÃO NO SISTEMA FAMILIAR ${ }^{1}$
}

\author{
Maria Olívia Dias ${ }^{2}$
}

\begin{abstract}
Resumo: Trazemos neste texto uma reflexão sobre a realidade familiar a partir de um olhar sistémico $e$ comunicativo sobre a convivência humana dos membros da família, tendo presente que cada membro está em interação com todos os outros. A visão sistémica e comunicacional procura entender as interações que ocorrem dentro do sistema familiar. Esta visão sistémica considera a família como um todo. Os membros da família ao interagirem e comunicarem estabelecem relações que servem para manter $o$ sistema em equilíbrio. $O$ desequilíbrio do sistema pode provocar desequilíbrio no indivíduo e vice-versa. Sendo a família um sistema de relações contínuas e interligadas, quando há mudança num membro da família, há mudança nos outros membros. Sabendo que uma pessoa vive diferentes sistemas, estes influenciam-se mutuamente. Assim, ao observarmos a família na perspetiva sistémica considerando o processo de comunicação no sistema familiar, quisemos analisar as dinâmicas que conduziram à mudança do sistema, os limites do conceito de família, aproximação sistémica da família e o processo de comunicação no sistema familiar.
\end{abstract}

Palavras-chave: Família, Sistema, Mudança, Processo, Comunicação

Abstract: In this paper the main aim is to reflect about families from a systemic and communicative perspective, and about human experience of family members, bearing in mind that each member is interacting with all others. The systemic view of communication seeks to understand the interactions that occur within the family system. This systemic view considers the family as a whole. Family members interact and communicate to establish relationships that serve to keep the

\footnotetext{
${ }^{1}$ Este artigo teve como base uma comunicação feita no encontro sobre: A Família um Sistema Dinâmico, organizado pela Comissão Política Distrital do Partido Social Democrata, Viseu, realizado em Mangualde no dia 16 de abril de 2011.

${ }^{2}$ Prof. Auxiliar do Departamento de Economia, Gestão e Ciências Sociais do Pólo de Viseu da Universidade Católica Portuguesa. E-mail: profaoliviadias@ gmail.com
} 
system in balance. The system imbalance may cause imbalance in the individual and vice versa. Since the family is a system of interconnected and continuous relations, when there is change in one family member, there's change in other members. Knowing that a person lives in different systems, they influence each other. Thus by looking at family systems perspective in considering the process of communication in the family system, we wanted to examine the dynamics that led to the change of the system, the limits of the concept of family, family systems approach and the communication process within the family system.

Keywords: Family, System, Change, Process, Communication

\section{INTRODUÇÃO}

A Unidade Maior do Crescimento Humano é a Família

Ao analisar a família na perspetiva sistémica e comunicacional não podemos deixar de ter em conta que nas últimas décadas o conceito de família tem vindo a adquirir um âmbito muito mais vasto, porque novas tendências, novas configurações familiares têm permitido novas conceções de família e da organização da vida dos seus membros, sendo valorizada por alguns nos seus hábitos tradicionais e por outros no seu progresso moderno.

Nas correntes modernas, mais liberais, realçam-se mais os sentimentos, o que interessa são os afetos, não interessa a biologia, secularizam-se as crianças. Segundo estas tendências deve promover-se a diversidade e a pluralidade; não deve haver padrões públicos; o Estado deve afastar-se de regulamentos, deve tratar de forma igual as diferentes formas de socialização, a pluralidade ao enquadramento das crianças. O Estado não deve colocar os seus poderes ou normas que privilegiam a família tradicional.

Para estes defensores é preciso deixar de lado a cultura do passado, os valores e os costumes e substituí-los, modernizando a família onde a coabitação é coisa igual ao casamento, às famílias divorciadas, recasadas, uniões de facto, uniões livres, homossexuais, crianças criadas por avós ou tios, etc. Tudo isto diz respeito aos dois parceiros em primeiro e só depois às crianças. As relações íntimas assentam no prazer, nos afetos, etc. (Simonato, 2010).

Tendo em conta estas realidades, a família não deixa de ser um sistema e ao mesmo tempo um processo de interação e de integração dos seus membros. A comunicação é o elo de ligação que constitui condição de convívio e de sustentação de todo o sistema, baseando-se na igualdade ou 
na diferença. A análise destas tendências explica-se pelo facto da família ter vindo a enfrentar um processo de profundas transformações ao longo dos tempos no sistema (Giddens, 2004: parte 4).

Seja qual for o modelo de família ela é sempre um conjunto de pessoas consideradas como unidade social, como um todo sistémico onde se estabelecem relações entre os seus membros e o meio exterior. Compreende-se, que a família constitui um sistema dinâmico, contém outros subsistemas em relação, desempenhando funções importantes na sociedade, como sejam, por exemplo, o afeto, a educação, a socialização e a função reprodutora. Ora, a família como sistema comunicacional contribui para a construção de soluções integradoras dos seus membros no sistema como um todo.

Parece-nos assim, estar suficientemente justificada a análise deste tema centrado na família. Assim sendo, num primeiro ponto veremos ainda que sumariamente, as dinâmicas que conduziram à mudança, o segundo, e pela multiplicidade de discursos que definem e concebem a família analisar-seão os limites do conceito. No terceiro abordaremos a família na perspetiva sistémica, e, por fim, concluímos com o processo de comunicação no sistema familiar.

\section{EVOLUÇÃO E MUDANÇA DA FAMÍLIA}

Alguns dos principais fundamentos teóricos associados à evolução e à mudança conduziram a novas conceções de família, novas dinâmicas, novos valores, diferentes tipos com identidade própria, construindo uma história de vida que não se pode replicar. As transformações levaram a alterações na família que deixou de ser um modelo tradicional prevalente, aparecendo novas formas de organização familiar tornando-se um fenómeno de caráter global e complexo (Dias, 2000: 82).

Novos conceitos de família, novas composições e funções, variação nas relações, estabilidade, diferente organização, a saída da mulher de casa para trabalhar fora e ter uma atividade económica, mesmo não sendo uma alternativa ao trabalho de casa, ou participar noutras ações sociais e políticas, foram consequências herdadas da mudança.

Evidentemente, que a evolução e a mudança que caraterizam de modo significativo o mundo atual não excluem a família. Embora considerada uma das instituições mais persistentes no tempo, a mudança social refletese amplamente na instituição familiar, arrastando-a desde os processos da industrialização e urbanização para novas realidades às quais tem procurado adaptar-se (Saraceno \& Naldini ${ }^{2} 2003$ : passim).

Esquematizando esta evolução que conduziu à mudança vemos como se alteraram as conceções de família, as dinâmicas e os valores (Fig. I): 
Figura I

Evolução e Fatores da Mudança

Novas concepções de família

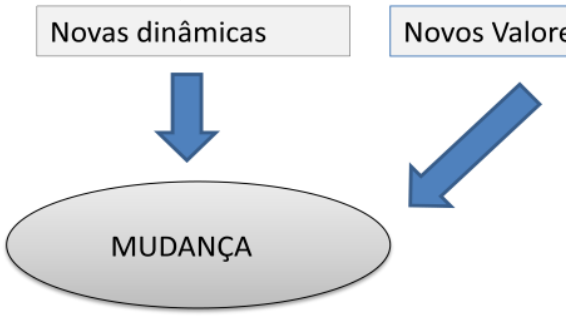

Foram os fatores económicos, políticos, sociais, culturais, demográficos e tecnológicos que contribuíram de forma decisiva para as alterações na estrutura e dinâmica familiar. Estes fatores tiveram incidência na organização, nas funções, nas relações, na complexidade e globalidade ao longo do desenvolvimento familiar, refletindo a evolução da época social, vivenciando estados diferentes (Dias, 2000: 82; Leandro, 2001: passim).

Ao longo do tempo modificou profundamente a estrutura, a dinâmica da família na sua organização interna, como por exemplo: diminuição do número médio de filhos, diminuição da fecundidade, aumento do número de pessoas sós, diminuição das famílias numerosas, aumento das famílias recompostas, em virtude do aumento do número de divórcios, aumento das uniões de facto e uniões livres, e, mais recentemente o aparecimento das famílias homossexuais.

Assistimos na evolução das famílias, e segundo o Fórum Democracia Aberta (2008), a motivos que como vemos originam novas configurações como se pode observar na Fig. II.

Figura II

Modelos de Família

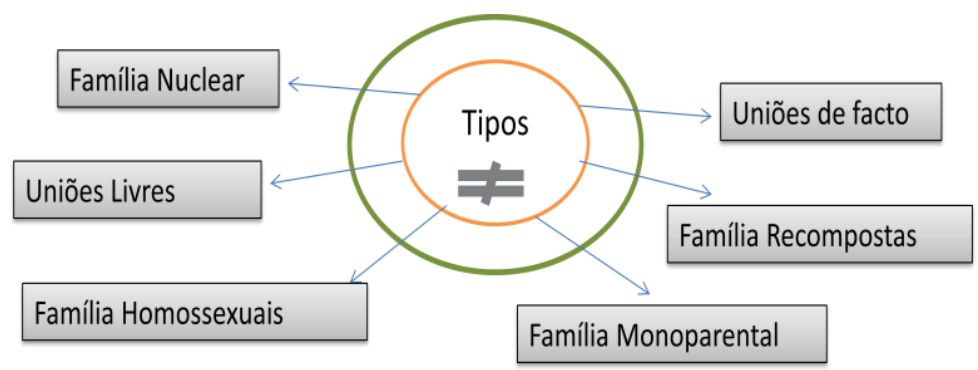


Os diferentes tipos de família são entidades dinâmicas com a sua própria identidade, compostas por membros unidos por laços de sanguinidade, de afetividade ou interesse e que convivem por um determinado espaço de tempo durante o qual constroem uma história de vida que é única e irreplicável (Giddens, 1999; 2004; Amaro, 2006: 71; Alarcão \& Relvas, 2002).

A família nuclear, constituída por dois adultos de sexo diferente e os respetivos filhos biológicos ou adotados, já não é para muitos o modelo de referência, embora continue a ser o mais presente.

As uniões de facto, trata-se de uma realidade semelhante ao casamento, no entanto não implica a existência de qualquer contrato escrito;

As uniões livres, não são muito diferentes das uniões de facto, apenas nestas nunca está presente a ideia de formar família com contratos;

As famílias recompostas são constituídas por laços conjugais após o divórcio ou separações. É frequente a existência de filhos de casamentos ou ligações diferentes ocasionando meios-irmãos;

As famílias monoparentais são compostas pela mãe ou pelo pai e os filhos. São famílias fruto de divórcio, viuvez ou da própria opção dos progenitores, mães solteiras, adoção por parte das mulheres ou dos homens sós, recurso a técnicas de reprodução. $\mathrm{O}$ aumento dos divórcios fez aumentar o número deste tipo de famílias já que nesta situação os filhos ficam a viver com um dos progenitores. Na maioria das vezes este progenitor é a mãe, embora já haja alguns homens;

Por fim, as famílias homossexuais constituídas por duas pessoas do mesmo sexo com ou sem filhos.

Se a evidência, no que concerne a um número crescente de diferentes tipos de famílias, é incontestável, estas novas formas de estrutura e dinâmica familiar não se despem, a nosso ver, da sua essência: a família como grupo social em que os seus membros coabitam ligados por uma ampla complexidade de relações interpessoais (Beltrão, apud, Dias, 2000: 81). Daí a importância que no passado e no presente se tem dado à família e às mudanças que a têm caracterizado na sua estrutura, nas relações dentro e fora dela.

Por outro lado, as diversas gerações que integram uma família avançam no tempo através do ciclo vital, priorizado por eventos que definem as diferentes etapas de crescimento, assim como as tarefas de socialização inerentes a cada um dos elementos no percurso que partilham em conjunto.

Em cada etapa têm lugar acontecimentos que determinam conjunturas que podem afetar cada um dos seus membros, o que exige dos intervenientes a necessidade de encontrarem novas formas de estar que 
lhes permitem adaptar-se às modificações estruturais, funcionais e às mudanças subjacentes a cada etapa.

Deste modo, o ciclo vital da família pode ser representado como um esquema de classificação em etapas, Fig. III, que demarcam uma sequência previsível de mudanças na organização familiar ao longo do tempo.

Figura III

Etapas da Vida Familiar

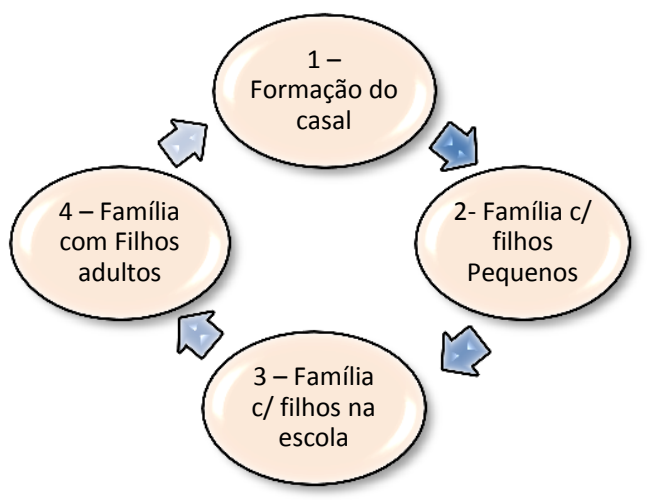

No esquema observamos que a família inicia com a constituição do casal e vai mudando à medida que nascem os filhos, se tornam alunos, adolescentes e adultos. $\mathrm{O}$ processo repete-se quando o primeiro filho sai de casa e forma nova família. O sistema altera-se, forma-se outro, as relações tornam-se mais abrangentes, constituindo-se um novo sistema familiar.

Quando as famílias têm dificuldades na adaptação, inerentes às diferentes etapas do ciclo, podem instalar-se "crises de desenvolvimento", caracterizadas por serem universais e previsíveis, gerando alterações na função familiar e problemas nos seus membros. A família desempenha neste ciclo um papel estabilizador, através do processo de socialização, o qual procura produzir nos indivíduos conformidade, por forma a que se adaptem à nova estrutura como um todo a que pertencem (Relvas, 1996: passim).

Embora os aspetos que acabamos de referir há que ter em conta a importância da transmissão dos valores pela família à medida que se vai transformado no seu ciclo vital. D. Teodoro, atualmente Bispo emérito da Madeira $^{3}$, dizia muitas vezes: o que a família não dá é difícil recuperar. $\mathrm{O}$ que se recebe quando se é criança não se apaga mais. Estas marcas permanecem para sempre e forjam os homens e as mulheres do amanhã.

\footnotetext{
${ }^{3}$ Reitor do Colégio Português em Roma no tempo em que fazíamos os nossos estudos.
} 
Ouvi-lhe estas palavras a quando do doutoramento na Gregoriana, em Roma e já lá vão 25 anos, ainda não as esqueci, quando trato de temas sobre a família recordo-as sempre.

\section{LIMITES DO CONCEITO DE FAMÍLIA}

É habitual quando pensamos em família, pensarmos na nossa família de origem, associamos ao lugar onde nascemos, crescemos e morremos, ainda que, nesse longo percurso possamos ir tendo mais de que uma família. Esta é, então, um espaço privilegiado para a elaboração e aprendizagens de dimensões significativas.

A representação mental que nos é evocada pela palavra família, núcleo constituído por pai, mãe e filhos, que partilham habitação, afetos, convívios quotidianos que se ajudam mutuamente, não é, de todo, uma realidade universal e transversal às diferentes sociedades e culturas, nem aos diferentes períodos que fomos vivendo ao longo da história da humanidade (Amaro, 2006; Gimeno, 2003: 39).

Pelo facto de o conceito não ser unívoco para todas as épocas e culturas, tornando-se difícil encontrar valores absolutos, as dificuldades associadas às várias dimensões familiares, relacionadas com a estrutura, com a funcionalidade e com as relações de cada modelo, leva-nos a pensar numa certa relatividade na definição do conceito de família.

A família, no sentido a que o nosso senso comum se refere, é uma construção social, uma vez que representa um modo de agir e de pensar coletivo, que evoluiu ao longo do tempo em relação com a organização e o funcionamento da sociedade (Silva, 2001).

Existem sociedades nas quais este conceito não tem aplicabilidade, pois a estrutura da organização das relações entre as pessoas é diferente, o que não significa inexistência de laços e regras familiares, traduz sim, normas diferentes de organização das relações homem - mulher, crianças - adultos.

Até aos anos cinquenta/sessenta, a ideia de família ocidental baseavase no conceito parsoniano, que a reconhecia como um espaço de estabilização emocional dos adultos e de socialização das crianças, isto é, transmissão dos valores culturais e sociais da sociedade em que nasceram.

$\mathrm{Na}$ convivência com o pai e a mãe a criança aprende como se deve comportar, o que lhe é permitido e proibido, bem como os papéis sociais que cabem aos diferentes elementos que constituem a família. Não sendo única a família é, na nossa sociedade, a primeira e mais forte instituição com caráter de socialização, em que a aprendizagem se realiza através da própria experiência da vida familiar (Amaro, 2006: passim). 
Os papéis sociais estavam bem demarcados, os homens trabalhavam fora de casa e asseguravam o sustento das famílias, às mulheres competia o trabalho doméstico e a socialização dos novos membros. Todos os elementos estavam subordinados ao chefe de família, esta autoridade não era apenas económica mas também moral (Silva, 2001).

A década de sessenta foi um marco de viragem na história da família das sociedades ocidentais. Num mundo em que as mulheres ocupavam postos de trabalho ao lado dos homens, já não era justificável a supremacia dos mesmos no interior do lar. Nesta época as mulheres reivindicaram o reconhecimento de direitos iguais aos dos homens em todos os planos da vida social, impondo o reconhecimento da partilha das tarefas familiares, uma vez que ambos exerciam profissões no exterior.

Atualmente, vivemos um período de grande mudança de valores e de organização social, decorrentes de uma série de fatores, como por exemplo o aumento da longevidade, a inversão da pirâmide demográfica, a emergência de novos valores e comportamentos, a dissociação entre casamento e iniciação sexual e a exigência do reconhecimento dos casamentos homossexuais de que já falamos.

A família de hoje já não traduz a construção mental que faz parte de cada um de nós, pai, mãe e filhos. Cada vez mais encontramos famílias "normais", à luz dos novos paradigmas, em que os membros nem sempre partilham a mesma residência, nem sempre os descendentes são filhos dos adultos da família e nem sempre os adultos são de sexos diferentes (Alarcão \& Relvas, 2002).

A família é uma rede complexa de emoções e relações que não são passíveis de ser pensadas como instrumentos criados para o estudo dos indivíduos isolados. Gameiro (cit. in Relvas, 1996: 11) afirma que “... a simples descrição de uma família não serve para transmitir a riqueza e a complexidade relacional desta estrutura".

Ainda que se tenham assumido novos paradigmas, referentes às novas estruturas de família e à igualdade de papéis na estruturação das suas atividades para todos os seus membros, é na mulher que continua a recair a maior parte das funções alusivas à organização interna da vida familiar; os trabalhos domésticos, os cuidados com as crianças e com as pessoas dependentes.

Estas considerações, a diversidade de modelos familiares, ao longo dos tempos e nas diferentes culturas, torna difícil atingirmos um consenso de definição única de família, mesmo que, intuitivamente, todos tenham em mente uma conceção e até uma atitude básica em relação a ela (Gimeno, 2003: 40).

Segundo o Instituto Nacional de Estatística a família é: "O conjunto de indivíduos que residem no mesmo alojamento e que têm relações de 
parentesco (de direito ou de facto) entre si, podendo ocupar a totalidade ou parte do alojamento. Considera-se também como família clássica qualquer pessoa independente que ocupa uma parte ou a totalidade de uma unidade de alojamento. Os empregados domésticos residentes no alojamento onde prestam serviço são integrados na respetiva família" (INE, 2002).

Em suma, a aproximação ao conceito fica distante daquela família como "unidade universal", é assim um termo com limites, muitas definições, uns privilegiam alguns elementos, outros privilegiam outros, estabelecem-se por vezes algumas clivagens entre os que pertencem e os que não pertencem. No entanto, é claro que a família procura estabilizar e perpetuar aspetos chave nos números e tipos de família. O conceito de família é relativo, não absoluto, qualquer definição é sempre incompleta e condicionada.

\section{FAMÍLIA SISTÉMICA E A DINÂMICA DOS SUBSISTEMAS}

Este terceiro ponto faz uma síntese da família como sistema formado por subsistemas que se influenciam interna e externamente num sistema aberto onde as influências são recíprocas (Alarcão, ${ }^{3} 2006$; Dias, 2000).

De acordo com a teoria geral dos sistemas, nada acontece isoladamente e qualquer coisa que afete um dos componentes, afeta todos os outros, ou seja, qualquer alteração causa impacto sobre todos os outros membros do sistema (Andrade \& Martins, 2011:188).

O sistema vem caracterizado essencialmente por três características:

Mínimo de interdependência entre os membros do sistema, o que significa que uma mudança num dos membros traz mudanças em cadeia;

Mínimo de regulamentos que presidem às relações entre os membros do sistema, o que significa que os seus vínculos obedecem a regularidades;

Mínimo de consciência dos regulamentos por parte do sistema, o que significa que no seu comportamento, cada um tem em conta essas regulações (Relvas, 1996; Gimeno, 2003; Amaro, 2006).

Depreende-se que a família satisfaz todos estes critérios e constitui provavelmente o exemplo mais acabado de sistema. A família é um sistema, ou seja, um conjunto de elementos ligados por um conjunto de relações em contínua relação com o exterior e mantendo o seu equilíbrio ao longo de um processo de desenvolvimento percorrido através de estados de evolução diversificados.

A teoria sistémica, que constitui o modelo predominante dos estudos da família, define-a como um sistema aberto, com uma finalidade e autorregulado. Sistema quer dizer uma unidade formada por membros que interagem entre si, havendo entre eles determinados vínculos e mantendo- 
se certas transações (Gimeno, 2003: 41; Amaro, 2006: 34). Assim, o sistema diz respeito à interdependência de todos os seus elementos, donde resulta a ideia de que o conhecimento da família só é possível se for adotada uma visão de conjunto.

A família na perspetiva sistémica ascende essencialmente a dois objetivos:

Um Interno - proteção psicossocial dos seus membros; outro Externo acomodação a uma cultura e transmissão dessa mesma cultura.

O sistema familiar é um todo, uma globalidade, em que o todo é mais do que a soma das suas partes (Amaro, 2006: 33). A família é um sistema, à semelhança de um organismo vivo e por isso deve ser analisada como um todo onde cada membro é o que é por si mesmo e pelas relações que estabelece com os outros. Os membros procuram definir para si e para os outros membros da família significados, o poder, a formação e distribuição de afetos.

Qualquer investigação, teórica ou empírica apresenta as características de um sistema, interpreta e explica o fenómeno através das ligações e interdependência entre si e organizam-se em totalidade, é por isso um fenómeno total que para funcionar em equilíbrio é essencial que todos os subsistemas se adaptem às exigências impostas pelas mudanças para que se consolidem as relações. Normalmente quando intervêm elementos perturbantes, a tendência é procurar recuperar o equilíbrio através da interiorização de valores consolidados (Parsons, 1979: 33).

Na perspetiva sistémica a família tem de ser vista como um sistema que apoia uma estrutura hierárquica dos seus membros, constituída em subsistemas, ou seja, um sistema dentro de outros sistemas e ela própria contendo outros sistemas com regras que regulam o relacionamento entre os membros da família (Fig. IV).

Figura IV

Sistema Familiar e Subsistemas

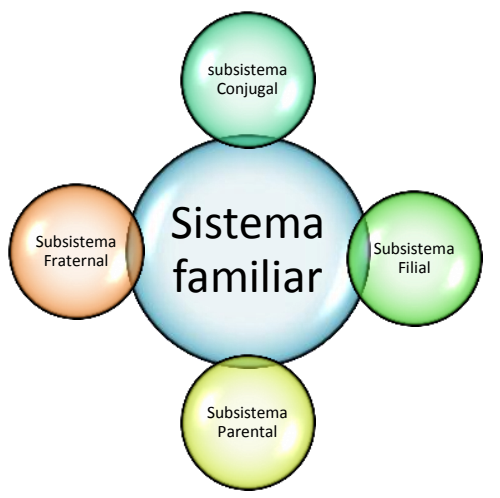


Assim, no subsistema conjugal há a presença do eu, tu, e nós marido e mulher. Surge quando dois adultos se unem numa relação interdependente e complementar, formando um casal, identifica as relações entre os cônjuges, poderá significar uma perda em individualidade mas um ganho em sentido de pertença, complementaridade, cooperação, simbiose. O subsistema filial, aparece com o nascimento do primeiro filho que modifica o sistema, seguindo-se outros filhos, hoje talvez o segundo, e raramente o terceiro. O subsistema parental tem como responsabilidade essencialmente a educação, a socialização, proteção a todos os níveis. Por fim o subsistema fraternal estabelece as relações entre os irmãos, que dentro da normalidade deveriam ser relações fortes descobrindo como cooperar (Relvas, 1996).

A forma como cada subsistema se organiza e como se desenvolvem as relações dentro de cada um, chama-se estrutura familiar. Todas as famílias se instituem através de uma estrutura de relações, esta organização é específica e única de cada família traduzindo, na prática, a forma como se organizam os diferentes elementos e se relacionam entre si. Nas palavras de Batista (2001), a estrutura familiar é fruto de transações $e$ comunicações repetidas que levam à definição de padrões de relação.

Cada família possui um dinamismo próprio que lhe confere, para além da sua individualidade, a sua autonomia. Contudo, integra influências externas, estando em parte dependente delas, não é simplesmente reativa às pressões do meio, pois está também sujeita a "forças internas" possuindo a capacidade auto-organizativa que lhe dá coerência e consistência neste jogo de equilíbrios dinâmicos como refere Alarcão ( $\left.{ }^{3} 2006\right)$.

Portanto, o sistema familiar não tem necessariamente um estatuto fixo, pois o ciclo vital da família sofre mudanças ao longo da vida familiar. Baseando-se no trabalho de Von Bertalanffy, os terapeutas familiares adotaram a ideia de família como um sistema aberto "...um sistema em troca de matéria como o meio, que apresenta entradas e saídas, construção e destruição dos seus componentes materiais" (1979: 149).

A família quando encarada como sistema aberto partilha determinadas propriedades sistémicas que se aplicam à interação (Alarcão, 2006; Batista, 2001): totalidade, feedback e equifinidade.

Totalidade - existe uma inter-relação e interdependência dos comportamentos de todos os elementos da família. Quando os elementos estão reunidos relacionam-se e comunicam entre si de maneira própria enquanto família, tornando-se diferentes de quando cada um está presente noutros contextos. Tem que se encarar a família como uma unidade que ultrapassa a soma dos seus elementos. A mudança num elemento 
repercute-se no sistema e o comportamento de cada um é indissociável do comportamento dos restantes;

Feedback - o sistema familiar reage à informação proveniente dos seus elementos e do ambiente, modificando o seu comportamento de forma a assegurar a sua continuidade;

Equifinidade - capacidade que o sistema desenvolve em centrar-se em torno de um objetivo ou finalidade comum.

Estas realidades permitem-nos acentuar a ideia de que a família não é um sistema estático, mas sim como um sistema dinâmico em permanente mudança e transformação.

Partindo desta descrição a família é vista como um sistema, isto é, uma ordem dinâmica de partes e processos entre os quais se exercem interações recíprocas sendo que, a família se torna um sistema aberto, constituído por muitas unidades presentes no sistema familiar, mas também no sistema social onde as relações entre estes dois sistemas permitem ora continuidade, ora mudança nos dois sistemas, atuando através de energias cibernéticas $^{4}$ (Fig. V).

\section{Figura V}

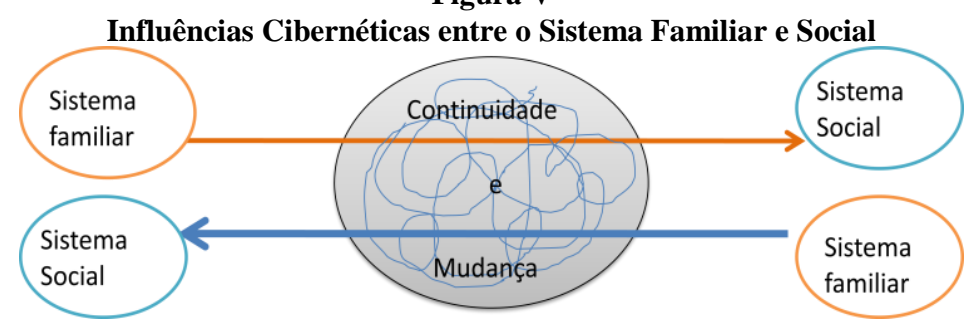

A família enquanto sistema aberto transforma-se numa unidade funcional para os seus membros, ao permitir o seu desenvolvimento e bem-estar através do intercâmbio entre o sistema familiar e o exterior, possibilitando que cada membro tenha as suas formas de se movimentar, realizar tarefas e funções que conduzem ao seu crescimento.

Todos os sistemas têm fronteiras que os ligam ao exterior sobre o qual atuam, sendo também influenciados pelo meio que os cerca. Estes dois sistemas estão sempre em transformação, são flexíveis adaptam-se e por isso complementam-se. Há uma relação dialética e recíproca nas influências e impactos entre si. Há nestes dois sistemas fatores que continuam e fatores que mudam familiar e socialmente.

\footnotetext{
${ }^{4}$ A cibernética, ou seja o estudo dos sistemas autorregulados com referência principal às máquinas. Os conceitos foram explorados e têm continuado a influenciar as nossas formas de explicar a interação nos sistemas humanos.
} 
É importante que o sistema familiar aberto funcione em equilíbrio. Para que isto aconteça é preciso que a presença de um conjunto de regras de comportamento e de funções dinâmicas se encontrem em constante interação entre elas, mas também, no intercâmbio do sistema familiar com o exterior (Alarcão, ${ }^{3}$ 2006; Bertanlannffy, 1979).

É sempre importante recordar que qualquer sistema pode ser descrito como um subsistema de um sistema mais vasto ou pode, ele próprio, ser subdividido em subsistemas que comunicam entre si tornando-se sistemas abertos que se influenciam reciprocamente.

Nesta perspetiva ousamos sublinhar que a família como sistema não é um agregado de "indivíduos" reunidos por um outro espaço de tempo, expostos a uma notícia, mas é um "grupo" corresponsável pelo bem de todos os seus membros de modo a que todos se sintam como fazendo parte deste todo. É fundamental para a estrutura, a dinâmica e o equilíbrio saudável do sistema, esta visão.

Esta dimensão da família é um valor cada vez mais premente, quando os interesses fora deste grupo representam muitos interesses individualistas, criando um dinamismo dentro e fora da família, inevitavelmente prejudicial dentro do sistema familiar e do sistema social

Sem um bom sistema familiar não há verdadeira construção da sociedade, sem partilhas recíprocas que assentem em valores, os sistemas desresponsabilizam-se e desequilibram os compromissos que têm. É por isso, que tanto o sistema familiar como o sistema social, equilibram e desequilibram em função da capacidade ou não para manter o sistema em equilíbrio, dando prioridade ao todo em detrimento das partes (Parsons, 1979).

\section{O PROCESSO DE COMUNICAÇÃO NO SISTEMA FAMILIAR}

Neste último ponto pretende-se evidenciar a importância da comunicação como expressão caracterizadora do sistema familiar e como fator determinante das relações familiares subjacentes no processo. É fundamental considerar o mecanismo de feedback, isto é, mecanismo de retorno ao ponto de origem da resposta do destinatário da informação, o que tem como consequência manter ou alterar o conteúdo da comunicação por parte do emissor (Amado, 2006: 35).

Neste sistema de comunicação podemos admitir que pode não haver coincidência entre o conteúdo da comunicação (mensagem) emitido pela fonte da comunicação e a mensagem percecionada pelo destinatário da comunicação. Isto deve-se a barreiras e obstáculos à comunicação, dificultando a compreensão do processo familiar, contribuindo por vezes 
para a instabilidade e o desequilíbrio do sistema. A comunicação entre todos os membros é importante entre todos os membros da família, tornase ainda mais relevante na relação progenitor filho porque a influência principal na vida moral dos filhos é essencialmente exercida pelos pais, sobretudo das crianças mais novas (Weissbourd, 2010). Estes bloqueios podem ser provenientes das competências comunicadoras do emissor e do recetor, no que se refere à forma como codificam e descodificam as mensagens, bem como à sua capacidade de raciocinar sobre os conteúdos das mesmas.

A família é, então, um espaço privilegiado para a elaboração e aprendizagens de dimensões significativas de interação e comunicação onde as emoções e afetos positivos ou negativos vão dando corpo ao sentimento de sermos quem somos e de pertencermos aquela e não a outra família (Relvas, 1996; Alarcão, ${ }^{3} 2006$ ).

Assim, o processo de comunicação na família sendo um sistema interativo onde o comportamento de cada indivíduo é fator e produto do comportamento dos outros, os resultados finais dependem menos das condições iniciais e mais do processo comunicativo (Fig. VI).

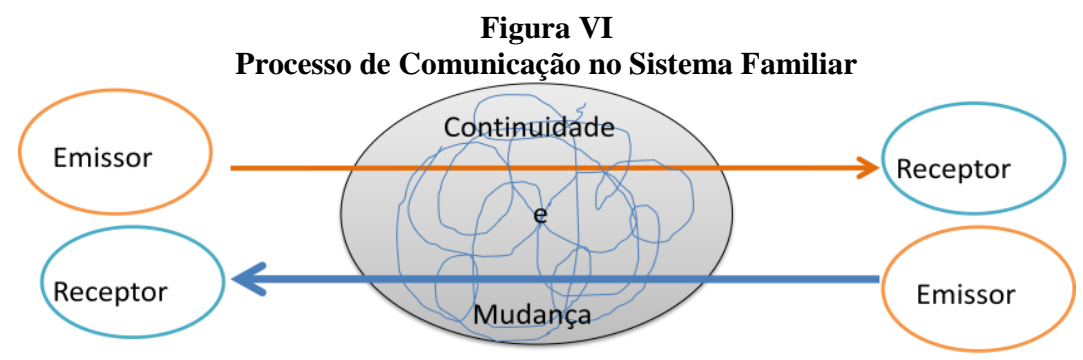

A família passa por um processo de desenvolvimento, o qual engloba a diferenciação estrutural - mudanças na organização relacional - e a coevolução - transformações relacionadas com a comunicação (Relvas, 1996). Ora durante este processo comunicativo há elementos que continuam e que dão consistência às relações, mas há também elementos que se transformam e dão origem a mudanças, sendo que no decurso das interações não há processos unilaterais, as relações são sempre bilaterais ou múltiplas.

A comunicação apresenta-se como fator determinante para facilitar as relações entre os membros da família e o meio social. A perspetiva sistémica da família é devedora do conceito pan-comunicacional proposto pela Escola de Palo Alto de que tudo é comunicação, no sentido em que a realidade humana e não humana, pode, converter-se em fluxos de comunicação, independentemente da intencionalidade de quem faz as emissões (Dias, 2001 $)$. 
Este exercício de comunicar estabelece uma relação, e, nesse sentido exige treino, reflexão, aprendizagem, prática e sobretudo uma série de atitudes e comportamentos que envolvem as palavras, o sentido compreensivo e lógico da estrutura, mas também os gestos, toda a linguagem do corpo. Estamos perante um conceito transdisciplinar que traz valor acrescentado essencialmente às Ciências Sociais e Humanas.

Neste contexto, depreendemos que comunicar subentende relação, promove capacidade de expressão que, para além de quebrar a solidão, é ligação a outrem, é satisfação das necessidades de ordem intelectual, afetiva, moral e social, constituindo uma componente essencial da vida de cada um em particular e em geral de todo o sistema familiar.

Se considerarmos o indivíduo como um sistema individual autoorganizado, o mesmo é dizer que se constrói na relação que estabelece com os outros. Visto que a relação caracteriza e expressa o sistema familiar, os sujeitos que dele fazem parte encontram-se num processo de comunicação constante, ao qual não podem subtrair-se. Como refere Watzlawick (1985: 44, apud Dias, 2001c): "não se pode não comunicar, ou seja, qualquer comportamento tem sempre o valor de mensagem, pelo que estamos sempre em processo de comunicação".

Com efeito, podemos dizer que na relação familiar, os membros que interagem se situam num plano sistémico e interativo de comunicação o indivíduo está permanentemente a fazer trocas entre o sistema familiar e o meio que o envolve cultural e socialmente, neste caso a família e a sociedade.

Desta forma, o processo de comunicação no sistema familiar conduz o indivíduo à adaptação social, caso contrário a relação familiar torna-se insustentável e a possibilidade do fracasso da sua integração no sistema familiar e no sistema social pode acontecer. O sistema familiar pode facilitar as trocas adaptativas ajustando as mudanças que se dão no meio ambiente. A comunicação torna-se assim parte integrante do indivíduo na família e na sociedade.

Como a família é a primeira instituição a facultar as relações o modo como nela se desenvolvem os processos de comunicação determinará o maior ou menor sucesso do desenvolvimento pessoal e social dos seus membros e, consequentemente, a integração na sociedade (Dias, 2002: 15 e $s s)$.

\section{CONCLUSÃO}

Da análise feita neste artigo podemos tirar algumas considerações:

A família não é do passado, a família é do passado, é do presente e será do futuro, mesmo que tenha de suportar as crises sociais, derivadas do 
próprio processo e dinâmica social, refletindo as mudanças tanto nas estruturas, como nas relações que definem a pessoa na família e na sociedade.

Apesar da família ser uma instituição universal e em todos existir uma ideia de família, temos dificuldade em dar uma definição. A palavra família estabelece associações com outros termos como casamento, ilhós, casa ou parentesco, e na realidade esses são elementos que aparecem em muitas definições de família. É difícil dar uma definição de família que satisfaça a todos, o conceito tem-se alterado ao longo dos tempos que dificulta representar todas as dimensões deste grupo social.

A evolução social determinou a evolução do conceito de família fazendo surgir novos tipos de organização familiar, onde variam a estrutura, a dinâmica, a cultura, as relações e funções tornando a sua compreensão mais complexa, global e por isso mais difícil de analisar.

Sabemos, no entanto, que a família se transforma através dos tempos adaptando-se e reestruturando-se para continuar a funcionar. A família é a matriz de desenvolvimento dos seus membros, no entanto temos de vê-la como um sistema dentro de outros sistemas inseridos num determinado contexto com uma cultura própria.

Sendo um grupo está sujeita a pressões tanto internas como externas para se acomodar às instituições sociais. Esta situação requer transformações constantes da posição dos membros no sistema familiar e no sistema social, sociedade e família, estabelecendo uma relação de influências mútuas.

A familia é o elemento mais firme, mais seguro e mais estruturante da personalidade dos seus membros. É o local privilegiado para a formação do caráter dos filhos, sendo que os adultos desempenham um papel decisivo no pleno desenvolvimento das capacidades, atitudes e valores que sustentam as competências do sistema como um todo. A comunicação é então o fator principal a estruturar pois é nela que assentam as práticas de interação formativa, relacional, educativa, de interação e integração social dos elementos que constituem.

Uma vez que as interações são várias, as relações familiares assentes em processos de comunicação permitem o equilíbrio do sistema familiar. Por outro lado, encarando a família como sistema ela permite através do processo de socialização interiorizar valores e as normas sociais para a sua formação e desenvolvimento (Relvas, 1996). Sendo um sistema aberto está sujeito a apreciações e influências em todo o processo comunicativo. Havendo relações familiares equilibradas o próprio processo sistémico permitirá o equilíbrio do sistema como um todo, ao mesmo tempo que estabelece uma ligação com a sociedade, contribuindo desta forma para o equilíbrio social. 


\section{BIBLIOGRAFIA}

ALARCÃO, M. (32006). (Des) Equilíbrios familiares: uma revisão sistémica Coimbra: Quarteto.

ALARCÃO M. \& RELVAS, A. P. (2002). Novas formas de família, Coimbra: Quarteto.

AMARO, F. (2006). Introdução à sociologia da família, Lisboa: Instituto Superior de Ciências Sociais e Políticas.

ANDRADE, A. \& MARTINS, R. (2011). "Funcionalidade familiar e qualidade de vida dos idosos" Millenium, no 40, p.185-199.

BAPTISTA, F. \& GARCÊS, I. (2001). "A família e intervenção social" in SILVA, Luísa (coord) Acção social na área fa família, Lisboa: Universidade Aberta.

BERTALANFFY, L. V. (1979). Perspectivas en la teoría general de sistemas, Madrid: Alianza.

DIAS, M. O. (2000). "A família numa sociedade em mudança problemas e influências" Gestão e desenvolvimento, $\mathrm{n}^{\circ}$ 9, Viseu: UCP. p. 81-102.

DIAS, F.N. (2001). Padrões de comunicação na família, uma análise sociológica, Lisboa: Instituto Piaget.

DIAS, F.N. (2002). Sociologia e toxicodependência, Lisboa: Instituto Piaget.

FORUM Democracia Aberta (2008). Evolução das famílias em Portugal [em linha]. Consultado em 12/07/2011. Disponível na World Wide Web

http://www.democraciaaberta.com/democracia_forum/ver_topico.ph $\mathrm{p} ? \mathrm{t}=295$.

GIDDENS, A. (1999). O mundo na era da globalização (trad. do inglês por Saul Barata), Lisboa: Presença.

GIDDENS, A. (2004). Sociologia, Lisboa: Fundação Calouste Gulbenkian.

GIMENO, A. (2003). A família - o desafio da diversidade, Lisboa: Instituto Piaget.

INSTITUTO Nacional de Estatística (2002). Censos 2001: resultados definitivos, Lisboa: INE.

LEANDRO, M. E. (2001). Sociologia da família nas sociedades contemporâneas, Lisboa: Universidade Aberta.

MARTINET, S. \& BAYLE, F. (2008). Perturbações da parentalidade, Lisboa: Climepsi.

PARSONS, T. (1979). The social system, New York: Free Press of Glencoe

RELVAS, A. P. (1996). O ciclo vital da família, perspectiva sistémica, Porto: Afrontamento. 
SARACENO, C. \& NALDINI, M. (2003). Sociologia da família, Lisboa: Editorial Estampa.

SILVA, L. (2001). Acção social na área da família, Lisboa: Universidade Aberta.

SIMONATO, M. \& OLIVEIRA, R. (2010). Funções e transformações da família ao longo da história. [em linha]. [Consultado em 12 de Julho de 2011]. Disponível em http://www.din.uem.br/ ulpeneto/outros/abppprnorte\%20(teste)/pdf/ a07Simionato03.pdf.

WEISSBOURD, R. (2010). Os pais que desejamos ser. Como os adultos bem intencionados podem prejudicar o desenvolvimento moral $e$ emocional da criança, Lisboa: Presença. 